\title{
Infective Phlebitis
}

National Cancer Institute

\section{Source}

National Cancer Institute. Infective Phlebitis. NCI Thesaurus. Code C78558.

Infection at the site of needle puncture or intravenous catheter placement due to poor aseptic techniques. It is characterized by erythema, pain, swelling, and induration at the catheter insertion site. 